уровень обеспеченности инновационными кадрами, поддерживающие и стимулирующие мероприятия в области активизации инновационной деятельности государства;

- оценка факторов успеха инновационной деятельности в отраслях АПК отдельных регионов РФ и перенос их лучшей практики;

- $\quad$ акцентирование внимания федерального центра при распределении дотаций и субсидий на активность инновационной деятельности отраслей АПК.

Апробации предлагаемой модели с целью ранжирования отраслей АПК по инновационной активности была проведена на территории Чеченской Республики, и результаты расчетов приведены на рисунке 1 .

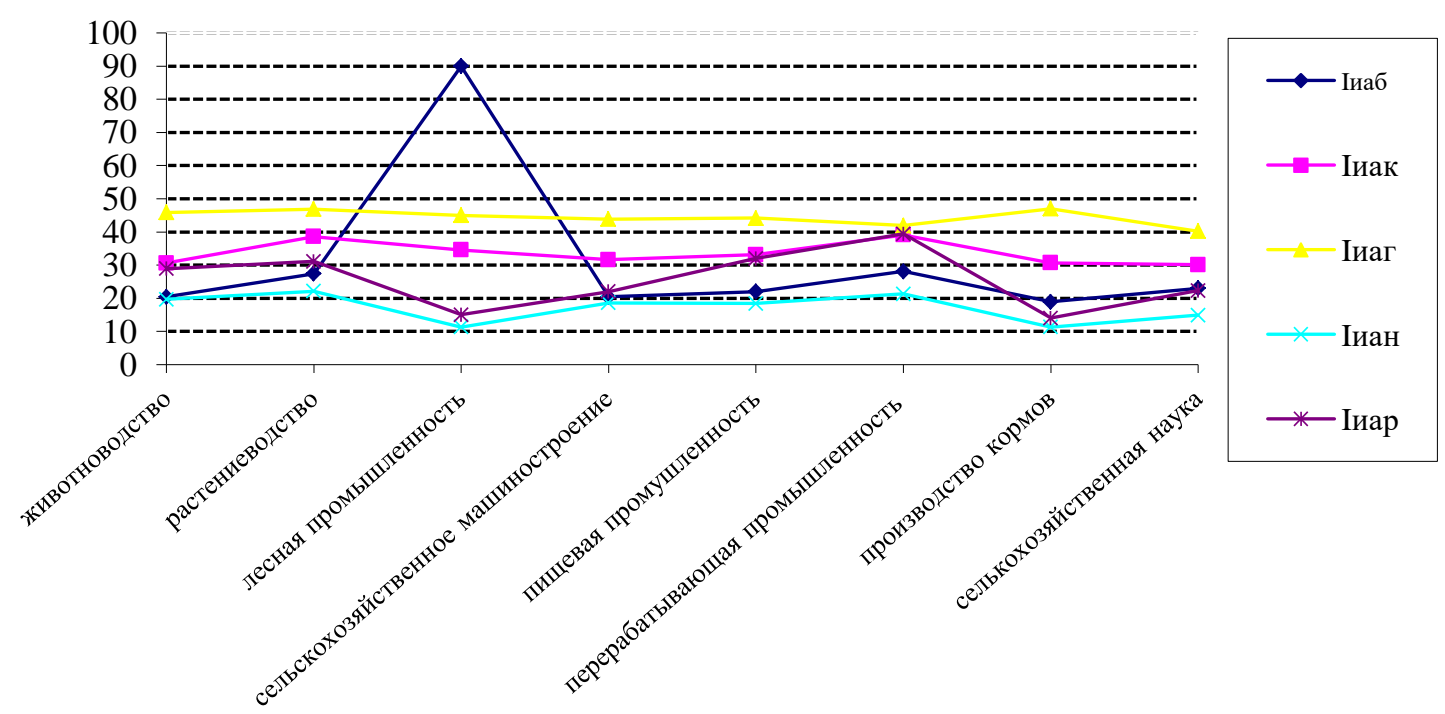

Рисунок 1. Распределение отраслей Ченченской Республики по уровню инновационной активности

Разработанная информационно-аналитическая модель оценки инновационной активности отраслей АПК позволит осуществить отбор отраслей АПК и оценить целесообразность формирования зон отраслевого развития (ЗОР) инновационного типа, путем поэтапного расчета социально-экономического положения, привлекательности отраслей АПК для потенциальных инвесторов и инновационной активности и потенциала в региональном АПК.

$$
* * *
$$

1. Алиева Л., Светлорусова Т. Инновационная система развития агропроизводственного рынка. АПК: экономика, управление, № 4, 2007, ст. 50-52

2. Гакаев Р. А. Роль природно-ресурсного потенциала в развитии экономики Чеченской Республики. Современные проблемы науки: сборник статей 1-й международной научно-практической конференции. Тамбов. 2008. С.40-43. В сборнике: Современные проблемы науки. Сборник статей 1-й международной научно-практической конференции. Тамбов. 2006. С. 45-50.

\title{
Расумов В.Ш. \\ Специфика региональных программ социально-экономического развития и их структура
}

ФГБОУ ВО «Чеченский государственный университет им. А.А. Кадырова» (Россия, Грозньй)

doi: $10.18411 /$ trnio-12-2021-55

\section{Аннотация}

Следует обозначить, что самой главной функцией органов исполнительной ветви власти на региональном уровне выступает формирование обоснованного с научной точки 
зрения прогноза, программы, плана развития региона на социальном и экономическом плане. На базе разработанных стратегий и программ устанавливаются соответствующие цели и задачи развития. Кроме того, конкретизируются различные программные мероприятия, определяются приоритеты в развитии хозяйственной деятельности региона.

Ключевые слова: социально-экономическое развития, программа, регион.

\section{Abstract}

It should be noted that the most important function of the executive branch of government at the regional level is the formation of a scientifically sound forecast, program, plan for the development of the region on the social and economic plane. Based on the developed strategies and programs, the corresponding development goals and objectives are established. In addition, various program activities are concretized, priorities in the development of economic activities in the region are determined.

Keywords: socio-economic development, program, region.

Одной из главных задач современного государства является регулирование регионального развития страны. Это позволяет повысить уровень социально-экономического развития территории, обеспечить хороший инвестиционный климат и т.д. Также целевые программы используются для управления и регулирования социального, научнотехнического и экономического развития. Особенность региональных программ заключается по сравнению с государственными программами небольшими объемами работ и затрат и имеют строгую целевую направленность.

Применение рассматриваемого метода в отношении региональных систем можно объяснить важностью придания максимальной степени конкретности целей и задач в качественной формулировке. Такие цели не имеют конкретного числового значения, однако при этом они являются теми ориентирами, по которым появляется возможность определить необходимый вектор программных действий.

Программа экономического и социального развития субъекта страны - это совокупность исследовательских, опытных, научных, организационных, социальных и прочих мероприятий. Именно они обеспечивают результативное разрешение различных задач в сфере экономического, культурного, экологического развития региона России.

Особую важность имеет так называемое региональное программирование. Оно представляет собой инструмент, с помощью которого государство влияет на рыночную экономику любого субъекта. При этом обеспечивается комбинация принципов самостоятельного регулирования его развития. Программно-целевой способ управления выступает важнейшим средством, с помощью которого государство воздействует на социальную и экономическую сферу проблемных субъектов. К таким регионам относятся те, которые недостаточно развиты, являются депрессивными или только осваиваются. Сюда также относятся развитые с промышленной точки зрения регионы. Благодаря рассматриваемому методу появляется возможность решать актуальные и стратегические задачи. Наиболее важной из них выступает выравнивание ступеней социальноэкономическое развитие на региональном уровне.

Отличительная черта программ экономического и социального развития субъекта заключается в том, что они сочетают в себе взаимодействие «свободного рынка» и «жесткой стратегии». В такой ситуации хоздеятельность ведется на коммерческой основе. Именно по этой причине организационные формы разработки и воплощения программ значительно отличаются от тех, которые использовались ранее.

Главные задачи программ социально-экономическое развитие на региональном уровне:

- выравнивание различий между регионами в соответствии с показателями экономико-социального развития;

_ _ разработка экономической структуры - как отраслевой, так и региональной; 
— результативное применение ресурсов субъекта;

— защита экологии;

_ разработка оптимальной инфраструктуры субъекта - как социальной, так и рыночной;

- стабилизация правовой, социальной, политической ситуации, охрана исторического наследия субъектов страны, их духовное развитие;

- ведение хоздеятельности субъектами страны в современных условиях.

Далее следует подробнее рассмотреть состав и систему программы социальноэкономического развития региона на региональном уровне. В данном случае под ними понимается основные направления, которые характеризуют реализуемый проект с функциональной и содержательной стороны. Эти направления должны отражать.

1. Изучение и оценка ситуации, которая сложилась на экономическом и социальном плане в том или ином субъекте. Здесь отражается такая ситуация, описываются ее вероятные последствия для территории. Также в данном разделе обозначены наиболее актуальные проблемы, которые необходимо решить.

2. Оценка состояния экологии. В данном разделе отражаются природные ресурсы, которые имеются в том или ином субъекте страны. Также указывается, как их можно использовать для определенных целей в рамках региона или для вывоза за его границы. Кроме того, в данном разделе описана экологическая обстановка, расписаны меры, направленные на ее улучшение. Также обозначены главные проблемы, которые необходимо решить.

3. Демографическая обстановка, рынок трудовой деятельности в рамках субъекта страны. В данном разделе отражается ситуация на рынке труда, обозначены основные проблемы в этой области, которые необходимо решить.

4. Концепция социально-экономического развития субъекта страны. Анализ и оценка рынка труда и природных ресурсов, которые проводились в прошлых разделах, дают возможность сформировать данную концепцию на будущий период.

5. Главные подпрограммы. Данный раздел содержит в себе главные подпрограммы для того или иного субъекта страны. Они могут разрабатываться в соответствии с разными признаками: функциональным, проблемным и прочими. Все перечисленные программы устанавливают приоритетные цели и задачи. В них также обозначены результаты, на достижение которых ориентированы те или иные меры.

6. Механизм непосредственной реализации программы. Тут предусмотрен полный комплекс действий, инструментов и мероприятий, направленных на решение той или иной проблемы. Такой механизм формируется на базе изучения и сравнения различных вариантов. Формируется прогнозный вариант программы.

7. Обеспечение программы ресурсами. Включает в себя вычисления расходов, которые потребуются для ее реализации. Отдельно выделяется часть ресурсов, которая относится к собственным источникам доходов.

8. Координация мероприятий, которые проводятся в рамках программы. Подразумевается согласование действий всех ее участников. Также данный раздел содержит обоснования по налаживанию сотрудничества субъекта, в рамках которого воплощаются программы, с другими регионами страны и даже с другими странами. 
9. Проводится оценивание реализации программы на предмет эффективности. Дается оценка каждого программного задания и программы в целом, для чего используется система показателей (качественных и количественных), в числе которых присутствуют показатели:

— целей, которых нужно было достигнуть при реализации программы; эффективности результатов, которые были получены в конечном итоге (абсолютные или сравнительные);

- специфические, содержание и необходимость которых обусловлена характером и особенностями, присущими каждой программе;

- выполнения работ согласно программе, в частности, прохождение этапов и получение промежуточных результатов;

- финансовых, трудовых, природных, временных затрат, которые требуются, чтобы выполнить задания, которые включает программа.

Кроме данного списка показателей проводится разработка мероприятий и работ в рамках программы, ее подпрограммы и другие показателей, которые нужны для того, чтобы управление программой было максимально эффективным.

10. Организация управленческого процесса программой, формы и методы для достижения целей управления. При разработке организационнофункциональной структуры управления обязательно учитываются особенности, которые присущи программе, региону.

$$
* * *
$$

1. Попов, Р.А. Региональное управление и территориальное планирование [Текст]: Учебник / Р.А. Попов. - М.: НИЦ ИНФРА-М, 2014. - 288 с.

2. Региональная экономика [Текст]: Учебное пособие / ред. В.Я. Позднякова. - М.: ИНФРА-М, 2016. - 576 с.

Расумов В.Ш., Джанхотова П.

Прогнозирование как социально-экономическое развитие региона

ФГБОУ ВО «Чеченский государственный университет им. А.А. Кадырова»

(Россия, Грозный)

doi: 10.18411/trnio-12-2021-56

\section{Аннотация}

На современном этапе развития многие регионы использовали все возможности экстенсивного развития, с чем и связано необходимость поиска интенсивного развития за счет применения инновационных подходов развития. В статье рассмотрены основные проблемы, связанные с прогнозированием социально-экономического развития региона.

Ключевые слова: прогнозирование, социально-экономическое развитие, регион.

\section{Abstract}

At the present stage of development, many regions have used all the possibilities of extensive development, which explains the need to search for intensive development through the use of innovative development approaches. The article discusses the main problems associated with forecasting the socio-economic development of the region.

Keywords: forecasting, socio-economic development, region.

Тенденции пространственного развития, сложившиеся в условиях экономического роста, оказались устойчивыми к внешним воздействиям, экономический кризис и послекризисное восстановление экономики не привели к существенному изменению пространственных пропорций производства и потребления, несмотря на то, что темпы кризисного снижения производства и послекризисного восстановления сильно 